\title{
Inhibition by soya isoflavones of human polymorphonuclear leukocyte function: possible relevance for the beneficial effects of soya intake
}

\author{
Serenella Rotondo ${ }^{1}$, Katarzyna Krauze-Brzósko ${ }^{1}$, Stefano Manarini ${ }^{1}$, Nicola Martelli ${ }^{1}$, Romina Pecce ${ }^{1}$, \\ Virgilio Evangelista ${ }^{1}$, Maria Benedetta Donati ${ }^{2}$ and Chiara Cerletti ${ }^{2} *$ \\ ${ }^{1}$ Laboratory of Vascular Biology and Pharmacology, Istituto di Ricerche Farmacologiche Mario Negri, Consorzio Mario \\ Negri Sud, Santa Maria Imbaro, Chieti, Italy \\ ${ }^{2}$ Research Laboratories, "John Paul II" Center for High Technology Research and Education in Biomedical Sciences, \\ Catholic University, Campobasso, Italy
}

(Received 23 March 2007 - Revised 12 June 2007 - Accepted 19 June 2007)

Lower CVD incidence is reported in Asian populations consuming soya-containing food. As polymorphonuclear leukocytes (PMN) are involved in the risk of CVD, we investigated the modulatory effect of soya isoflavones on several PMN functions and their molecular mechanisms in vitro. PMN, isolated from blood from healthy subjects, were tested upon activation with $1 \mu \mathrm{M}$ - $\mathrm{n}$-formyl-methyl-leucyl-phenylalanine (fMLP) for superoxide anion production (ferric cytochrome c reduction) and released elastase (chromogenic test). PMN homotypic aggregates stimulated by fMLP or P-selectin in dynamic conditions were detected by optical microscopy. PMN, mixed with thrombin-activated, washed platelets, formed cell aggregates, measured by flow cytometry. Phosphorylation of Pyk2, a focal adhesion kinase, was studied by immunoprecipitation and immunoblotting with specific antibodies. Genistein, daidzein and equol inhibited superoxide anion production $\left(\mathrm{IC}_{50} 0 \cdot 25\right.$ (SEM $0 \cdot 1$ ), 21.0 (SEM 4.2) and 13.0 (SEM 2.8) $\mu \mathrm{M}$, respectively); the release of elastase was prevented by genistein ( $\mathrm{IC}_{50} 63$ (SEM 17) $\mu \mathrm{M}$ ). PMN homotypic aggregates, stimulated by fMLP, were significantly reduced (24 (SEM 12) and 51 (SEM 14) \% of control) by $100 \mu \mathrm{M}$ genistein and equol. P-selectin-induced aggregates were reduced to 19 (SEM 6), 44 (SEM 10) and 28 (SEM 9) \% of control by $100 \mu \mathrm{M}$ genistein, daidzein and equol, respectively. Genistein, daidzein and equol also significantly reduced mixed platelet-PMN aggregates ( IC $_{50} 4.0$ (SEM 0.9), 57 (SEM 6) and 66 (SEM 23) $\mu$ M, respectively). In PMN challenged by fMLP or P-selectin, activation of Pyk2 was prevented by isoflavones. The cardioprotective effect of soya-containing food might be linked to reduction of PMN activation and PMN-platelet interaction, novel targets for the biological effects of soya isoflavones.

Soya isoflavones: Polymorphonuclear leukocytes

Epidemiological data suggest an association between the number of leukocytes, polymorphonuclear leukocytes (PMN) in particular, and the risk of ischaemic vascular disease ${ }^{1-3}$. Activated leukocytes have been reported in the systemic circulation of patients after myocardial infarction ${ }^{4}$ or coronary angioplasty ${ }^{5}$. Platelet/leukocyte interactions and leukocyte incorporation into and/or on to thrombi have been observed in different experimental models. While thrombocytopenia decreases leukocyte recruitment after vascular injury in a porcine model $^{6}$, platelet accumulation in experimental myocardial infarction is reduced by PMN depletion ${ }^{7}$. In animal models of myocardial infarction, PMN depletion, pharmacological suppression of PMN activation, as well as inhibition of PMN-endothelial cell interactions, reduced the extent of acute tissue injury and mortality following ischaemia and reperfusion $^{8,9}$.

Activated PMN can be responsible for several manifestations of IHD due to their ability to produce and release reactive oxygen species, leukotriens and proteolytic enzymes, which can directly induce vascular damage and/or influence the activation state of platelets and endothelial cells ${ }^{10}$.

Many common diseases are diet-related and could benefit from diets rich in compounds that down regulate PMN function. Asian populations consuming soya-containing food have reportedly a lower incidence of CVD than people from Western countries ${ }^{11}$.

Among soya components, the isoflavones genistin and daidzin are bound to glucose and, when ingested by man, are enzymatically cleaved by the gut microflora to their respective active forms: genistein; daidzein ${ }^{12}$. Daidzein is then converted to equol, another isoflavon. Soya isoflavones are also referred to as phyto-oestrogens because of the presence of a phenolic ring, which enables them to bind to oestrogen receptors in human individuals, but their mechanism of action is not exclusively hormonal, including antioxidant, antiproliferative and antiangiogenic activities ${ }^{13}$.

Abbreviations: BCECF, 2' $2^{\prime} 7^{\prime}$-bis-(2-carboxyethyl)-5(6)-carboxyfluorescein; DMSO, dimethyl sulphoxide; EGTA, ethylene glycol-bis ( $\beta$-aminoethyl ether)$\mathrm{N}, \mathrm{N}, \mathrm{N}^{\prime}, \mathrm{N}^{\prime}$-tetraacetic acid; fMLP, n-formyl-methyl-leucyl-phenylalanine; HT, HEPES-Tyrode; MoAb, mouse monoclonal antibody; PFA, paraformaldehyde; PMA, phorbol-myristate-acetate; PMN, Polymorphonuclear leukocytes.

* Corresponding author: Dr. Chiara Cerletti, fax +390874 312710, email ccerletti@rm.unicatt.it 
The aim of the present study was to investigate the capacity of soya isoflavones to modulate in vitro PMN function, as well as homotypic and heterotypic PMN interactions.

\section{Experimental methods}

\section{Materials}

Genistein, daidzein and equol were purchased from Extrasynthèse (Genay, France). HEPES, PGE1, ethylene glycol-bis ( $\beta$-aminoethyl ether)- $\mathrm{N}, \mathrm{N}, \mathrm{N}^{\prime}, \mathrm{N}^{\prime}$-tetraacetic acid (EGTA), $2^{\prime}, 7^{\prime}$ bis-(2-carboxyethyl)-5(6)-carboxy-fluorescein, cytochalasin $\mathrm{B}$, ferric cytochrome c, n-formyl-methyl-leucyl-phenylalanine (fMLP), phorbol-myristate-acetate (PMA), fluorescein isothiocyanote (FITC)-conjugated anti-Mac-1 mouse monoclonal antibody (MoAb), thrombin from human plasma (2000 National Institute of Health U/mg protein), N-succinyl-AlaAla-Val-p-nitroanilide were from Sigma Chemical Co. (St. Louis, MO, USA). Dextran T500 and Ficoll Hypaque were from Pharmacia Fine Chemicals (Uppsala, Sweden). Hydroxyetidine was from Molecular Probes Europe (Leiden, The Netherlands), paraformaldehyde (PFA) from Fluka (Milano, Italy). Soluble human P-selectin was purified from fresh platelet lysates by immunoaffinity using the anti-P-selectin MoAb WAPS $12 \cdot 2$, purified from mouse ascites or hybridoma cell (American Tissue Type Colture Collection, Manassas, VA, USA) supernatants, using protein G-sepharose affinity columns. The anti-phosphotyrosine PY99 and the anti-Pyk2 (C19) antibodies were from Santa Cruz Biotechnology (Santa Cruz, CA, USA). The enhanced Chemi-Luminescence Western blotting system (ECL-kit) was from Amersham Life Science (Little Chalfont, Buckinghamshire, UK). Reagents for electrophoresis and Western blot analysis were pure grade. IMLP and PMA were dissolved in dimethyl sulphoxide (DMSO), stored at $-20^{\circ} \mathrm{C}$ and diluted in isotonic saline just before use. Thrombin was dissolved in saline at concentrations of $50 \mathrm{U} / \mathrm{ml}$ and stored at $-20^{\circ} \mathrm{C}$ until use. Soya isoflavones were dissolved in DMSO just before use. The final concentration of DMSO in samples was always $\leq 0.5 \%(\mathrm{v} / \mathrm{v})$. In each experiment, the control group was tested in the presence of an equivalent dilution of DMSO.

\section{Preparation of polymorphonuclear leukocytes and platelets}

Human blood was collected from healthy volunteers who had not received any medication for at least 2 weeks. Nine parts of blood were anticoagulated with one part of $3.8 \%$ trisodium citrate. Cells were isolated from whole blood using standard procedures performed at room temperature ${ }^{14}$. Briefly, platelet-rich plasma was prepared by centrifuging whole blood at $250 \mathrm{~g}$ for $25 \mathrm{~min}$. PMN were isolated from the remaining blood by dextran sedimentation, followed by Ficoll-Hypaque gradient and hypotonic lysis of erythrocytes. PMN were washed and resuspended in HEPES-Tyrode (HT) buffer (129 mM-NaCl, 9.9 mM-NaHCO $3,2.8 \mathrm{~mm}-\mathrm{KCl}, 0.8 \mathrm{~mm}-\mathrm{KH}_{2} \mathrm{PO}_{4}$, $5.6 \mathrm{mM}$-dextrose, $10 \mathrm{~mm}$-HEPES, in bidistilled water) added with $1 \mathrm{~mm}-\mathrm{CaCl}_{2}$ and $1 \mathrm{mM}-\mathrm{MgCl}_{2}$.

PMN suspensions contained $95 \%$ PMN and an average of one platelet per thirty PMN.

For adhesion experiments, PMN were stained with the vital red fluorescent dye hydroxyetidine $(20 \mu \mathrm{g} / \mathrm{ml}$ per
$5 \times 10^{7} \mathrm{PMN} / \mathrm{ml}$ ) for $30 \mathrm{~min}$ at $4^{\circ} \mathrm{C}$. Platelets were loaded with the green fluorescent dye $2^{\prime}, 7^{\prime}$-bis-(2-carboxyethyl)5(6)-carboxyfluorescein (BCECF), by incubating platelet-rich plasma with $2 \mu \mathrm{g} / \mathrm{ml}$ of its acetoxymethyl ester ( $2^{\prime}, 7^{\prime}$-bis-(2carboxyethyl)-5(6)-carboxyfluorescein) for $30 \mathrm{~min}$ at $37^{\circ} \mathrm{C}$. After two washes in the presence of $2 \mu \mathrm{M}-\mathrm{PGE} 1$ and $5 \mathrm{~mm}-$ EGTA, the BCECF-loaded platelets were resuspended in HT buffer added with $1 \mathrm{~mm}-\mathrm{CaCl}_{2}$ and $1 \mathrm{mM}-\mathrm{MgCl}_{2}$, at $1 \times 10^{9}$ platelets $/ \mathrm{ml}$. Platelets were stimulated with thrombin $0.5 \mathrm{U} / \mathrm{ml}$ for $2 \mathrm{~min}$ at room temperature and fixed with one volume of $2 \%$ PFA at room temperature for $1 \mathrm{~h}$. After fixation, platelets were washed and resuspended in the same medium with $1 \mathrm{~mm}-\mathrm{CaCl}_{2}$ and $1 \mathrm{~mm}-\mathrm{MgCl}_{2}$, at $1 \times 10^{8}$ cells $/ \mathrm{ml}$.

\section{Experimental conditions}

All the experiments (except superoxide anion production) have been performed in the following experimental conditions (standard conditions). Cells were incubated in a final volume of $500 \mu \mathrm{l}$, in siliconized glass tubes (internal diameter $6 \mathrm{~mm}$; ChronoLog, Mascia Brunelli, Milano, Italy) and the tubes were placed in an aggregometer (Platelet Ionized Calcium Aggregometer, PICA; ChronoLog) at $37^{\circ} \mathrm{C}$ with stirring at $1000 \mathrm{rpm}$. Although the shear rate produced by this stirring speed cannot be precisely quantified, it should be approximately 250 per $\mathrm{s}^{15}$.

\section{Measurement of superoxide anion production}

Superoxide anion production was determined by measuring the reduction of ferric cytochrome $\mathrm{c}^{16}$. PMN $\left(1 \times 10^{7} / \mathrm{ml}\right)$, in the presence of $2.5 \mu \mathrm{g} / \mathrm{ml}$ cytochalasin B and $20 \mathrm{nmol}$ ferric cytochrome c, were pre-incubated in a 96-well microtitre plate with DMSO (control) or with different concentrations of soya isoflavones for $5 \mathrm{~min}$ at room temperature, before stimulation with $1 \mu \mathrm{M}$-fMLP or $100 \mathrm{nM}-\mathrm{PMA}$ for $40 \mathrm{~min}$. Basal superoxide anion production from unstimulated PMN was assessed in samples incubated with DMSO, cytochalasin B and ferric cytochrome c, but without fMLP. Thereafter, absorbance was measured simultaneously at 550 and $540 \mathrm{~nm}$ with Multiskan spectrophotometer (Titertek Labsystems, Basingstoke, UK) and the resulting ratio expressed as nanomoles of ferric cytochrome c reduced by $10^{6} \mathrm{PMN}$ in $40 \mathrm{~min}$

\section{Polymorphonuclear leukocyte elastase activity assay}

Elastase activity, released in supernatants from PMN, was assayed spectrophotometrically by monitoring the rate of release of p-nitroanilide from the specific chromogenic substrate N-succinyl-Ala-Ala-Val-p-nitroanilide at $410 \mathrm{~nm}$ in 5 -min kinetics ${ }^{14}$. PMN were pre-incubated with DMSO or different concentrations of soya isoflavones for $5 \mathrm{~min}$ at room temperature, in the presence of cytochalasin B $(2.5 \mu \mathrm{g} /$ $\mathrm{ml}$ ), before stimulation with $1 \mu \mathrm{M}$-fMLP; after 3 min samples were centrifuged and supernatants used to measure enzyme release. Elastase concentration was extrapolated from a standard curve of known concentrations of purified human elastase. Results are presented as \% of controls. 


\section{Polymorphonuclear leukocyte aggregation experiments}

Samples of washed PMN $\left(500 \mu 1,1 \times 10^{7} / \mathrm{ml}\right)$ in HT buffer, containing $\mathrm{CaCl}_{2}$ and $\mathrm{MgCl}_{2}$ (1 mM each), were pre-incubated with DMSO (control) or different concentrations of soya isoflavones for $5 \mathrm{~min}$ at room temperature. Cell suspensions were stimulated ( $1 \mu \mathrm{M}$-fMLP or $25 \mu \mathrm{g} / \mathrm{ml}$ soluble P-selectin), for 3 min in standard conditions. Aliquots of the PMN suspension $(50 \mu \mathrm{l})$ were then fixed with PFA (1\% final concentration) and the single, non-aggregated PMN were counted under contrast light microscopy. The number of single PMN counted before and after stimulation was used to calculate the percentage of aggregated PMN. Results are presented as \% of control.

\section{Double colour flow cytometric assay of polymorphonuclear} leukocyte-platelet adhesion

A previously described methodology has been used ${ }^{17,18}$. Briefly, hydroxyetidine-loaded PMN $\left(1 \times 10^{7} / \mathrm{ml}\right)$ were preincubated with DMSO (control) or soya isoflavones for $5 \mathrm{~min}$ at room temperature, then they were placed to interact with an equal volume of BCECF-loaded, thrombin-activated fixed platelets $\left(1 \times 10^{8} / \mathrm{ml}\right)$, under stirring at $1000 \mathrm{rpm}$, at $37^{\circ} \mathrm{C}$, in the aggregometer. Cell interaction was stopped after 1 min with one volume of $2 \%$ PFA and samples kept at $4^{\circ} \mathrm{C}$ in the dark and analysed within $1 \mathrm{~h}$ by FACStar flow cytometer (Becton Dickinson, Milano, Italy) with an argonion laser operated at $400 \mathrm{~mW}$ output power.

PMN were identified on the basis of forward and side scatter alone or in combination with the specific red fluorescent marker. Gating on events identified as PMN was performed in order to exclude single platelets. For each experiment, the threshold of adhesion was set on the green fluorescence scale by use of a sample of mixed cells in the presence of $10 \mathrm{~mm}$-EGTA. Platelet adhesion was quantified by evaluating the relative number of platelets bound to $100 \mathrm{PMN}$ (platelets/100 PMN), as described ${ }^{17}$. Results are presented as \% of control.

Flow cytometric analysis of Mac-1 expression on polymorphonuclear leukocyte surface

Samples of washed PMN $\left(1 \times 10^{7} / \mathrm{ml}\right)$ in HT buffer containing $\mathrm{CaCl}_{2}$ and $\mathrm{MgCl}_{2}$ (1 mM each) were incubated with DMSO (control) or with different concentrations of soya isoflavones for $5 \mathrm{~min}$ at room temperature and therefore stimulated for 3 min with $1 \mu \mathrm{M}$-fMLP, in standard conditions. After stimulation, $100 \mu \mathrm{l}$ sample aliquots were incubated with a FITCconjugated anti-Mac-1 MoAb, for $30 \mathrm{~min}$ at $4^{\circ} \mathrm{C}$. Incubation was blocked by adding $1 \mathrm{ml}$ ice-cold HT buffer. PMN fluorescence was analysed by a FACStar flow cytometer as previously described ${ }^{17}$. Acquisition and processing of data from 5000 cells was carried out with a Consort 30 Program (Becton Dickinson) on a Hewlett Packard 300 computer. Labelling with anti-Mac-1 MoAb was evaluated as mean fluorescence intensity in arbitrary units.

\section{Pyk2 tyrosine phosphorylation}

PMN, pretreated with $5 \mathrm{mM}$-di-isopropyl fluorophosphates to inhibit intracellular proteases, were incubated with DMSO or soya isoflavones for $5 \mathrm{~min}$ before stimulation with
$1 \mu \mathrm{M}$-fMLP or $25 \mu \mathrm{g} / \mathrm{ml}$ soluble P-selectin. PMN were stirred at $1000 \mathrm{rpm}$ for $3 \mathrm{~min}$ at $37^{\circ} \mathrm{C}$ and then lysed in reducing Laemmli's buffer containing protease and phosphatase inhibitors. The samples were boiled for $10 \mathrm{~min}$ and diluted 1:20 with $1 \%$ Triton X-100 lysis buffer (1\% Triton X-100, $150 \mathrm{~mm}-$ $\mathrm{NaCl}$ and $25 \mathrm{~mm}-\mathrm{Tris}-\mathrm{Hcl}, \mathrm{pH} 7.4)$ containing protease and phosphatase inhibitors. After pre-clearing with Protein G-Sepharose, the samples were incubated at $4^{\circ} \mathrm{C}$ overnight with $10 \mu \mathrm{g} / \mathrm{ml}$ anti-Pyk2 antibody and Protein G-Sepharose. The immunoprecipitates were analysed by immunoblotting with either $0 \cdot 1 \mu \mathrm{g} / \mathrm{ml}$ anti-Pyk2 (which recognizes whole Pyk2 protein) or PY99 (which recognizes phosphorylated tyrosines) antibody ${ }^{19,20}$.

\section{Statistical analysis}

Data are presented as means with their standard errors of the mean. One-way ANOVA was followed by Dunnett's multiple comparison test; $P$ values of 0.05 or lower were considered significant. $\mathrm{IC}_{50}$ values (i.e. the concentration of compounds required to produce $50 \%$ of inhibition of maximal response) were calculated using a Mac Allfit computer program.

\section{Results}

\section{Effect on superoxide anion production}

Superoxide anions produced by $1 \times 10^{6} \mathrm{PMN}$ within $40 \mathrm{~min}$ resulted in the reduction of 0.25 (SEM 0.08) nmol cytochrome c. This amount rose to 11.0 (SEM 1.4) and 19.1 (SEM 1.3) upon cell stimulation with $1 \mu \mathrm{M}$-fMLP or $100 \mathrm{nM}-\mathrm{PMA}$, respectively (n 3).

Genistein, daidzein and equol inhibited fMLP-induced production of superoxide anions in a concentration-dependent manner with $\mathrm{IC}_{50} 0 \cdot 25$ (SEM 0.1), 21.0 (SEM 4.2) and 13.0 (SEM 2.8) $\mu \mathrm{M}$, respectively (Fig. 1). The amounts of

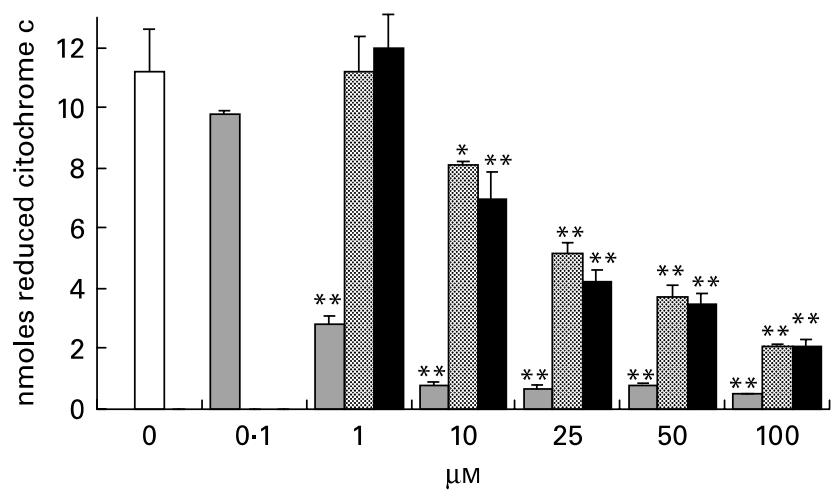

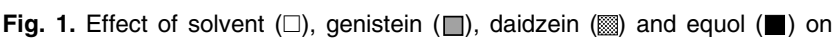
superoxide anion production by polymorphonuclear leukocytes (PMN) stimulated with n-formyl-methyl-leucyl-phenylalanine (fMLP). PMN, in the presence of $2.5 \mu \mathrm{g} / \mathrm{ml}$ cytochalasin $B$ and $20 \mathrm{nmol}$ ferric cytochrome $\mathrm{c}$, were preincubated in a 96-well microtitre plate with different concentrations of soya isoflavones or with dimethyl sulphoxide (control) or for $5 \mathrm{~min}$ at room temperature, before stimulation with $1 \mu \mathrm{M}$-fMLP for $40 \mathrm{~min}$. Values are presented as nanomoles of ferric cytochrome c reduced by $10^{6} \mathrm{PMN}$ for $40 \mathrm{~min}$; basal (unstimulated) values of anion production were 1 (SEM 0.1) nmol ferric cytochrome $\mathrm{C}$ reduced by $10^{6} \mathrm{PMN}$ for $40 \mathrm{~min}$. Values are means with their standard errors of the mean $(n 3)$. Mean values were significantly different compared with control values; ${ }^{*} P<0.05 ;{ }^{*} P<0.001$. For details of procedures, see Experimental methods. 
cytochrome $\mathrm{c}$ reduced by superoxide anions from fMLPstimulated PMN in the presence of $100 \mu \mathrm{M}$ genistein, daidzein or equol were 0.6 (SEM 0.03), 2.0 (SEM 0.07) and 2.1 (SEM 0.2) nmol, respectively. None of the isoflavones inhibited PMA-induced production of superoxide anions. In fact, the amounts of cytochrome c reduced by superoxide anions from PMA-stimulated PMN in the presence of $100 \mu \mathrm{M}$ genistein, daidzein or equol were 17.0 (SEM 1.7), 17.8 (SEM 2.5) and 16.2 (SEM 2.0) nmol, respectively (not significantly different from 19.1 (SEM 1.3) nmol in control samples, $n$ 3).

\section{Effect on elastase release}

Genistein $(5-100 \mu \mathrm{M})$ inhibited the release of elastase from PMN stimulated for $3 \mathrm{~min}$ with $1 \mu \mathrm{M}$-fMLP in a concentration-dependent manner, with an $\mathrm{IC}_{50} 63$ (SEM 17) $\mu \mathrm{M}$ ( $n$ 3; $P<0.05$ both at 50 and $100 \mu \mathrm{M}$ ); daidzein slightly affected this process at the highest concentration (88 (SEM 4) $\%$ of control, at $100 \mu \mathrm{M}, n 3$ ), while equol was ineffective (data not shown).
Effect on homotypic polymorphonuclear leukocyte adhesion induced by n-formyl-methyl-leucyl-phenylalanine or soluble $P$-selectin

PMN stimulation by $1 \mu \mathrm{M}-\mathrm{fMLP}$ induced aggregate formation, where 66 (SEM 12) \% of PMN were recruited ( $n$ 5). Aggregated PMN was reduced to 24 (SEM 12) $\%$ and 51 (SEM 14) $\%$ of PMN recruited by $100 \mu \mathrm{M}$ genistein and equol, respectively (Fig. 2(a), reporting values as percentage of controls, in the absence of isoflavones). The inhibition by daidzein was not statistically significant.

Stimulation for $3 \mathrm{~min}$ with P-selectin induced the formation of aggregates, where 63 (SEM 10) \% of PMN were recruited $(n 6)$. Genistein, daidzein or equol inhibited P-selectin-induced PMN aggregation in a concentrationdependent manner (Fig. 2(b), reporting values as percentage of controls, in the absence of isoflavones). The $\mathrm{IC}_{50}$ for genistein and equol were 7.5 (SEM 1.5) and 85 (SEM 22) $\mu \mathrm{M}$, respectively ( $n$ 6). Aggregated PMN was reduced from 63 (SEM 10) $\%$ to 19 (SEM 6), 44 (SEM 10) and 28 (SEM 9) $\%$ after pre-incubation with $100 \mu \mathrm{M}$ genistein, daidzein, or equol, respectively.
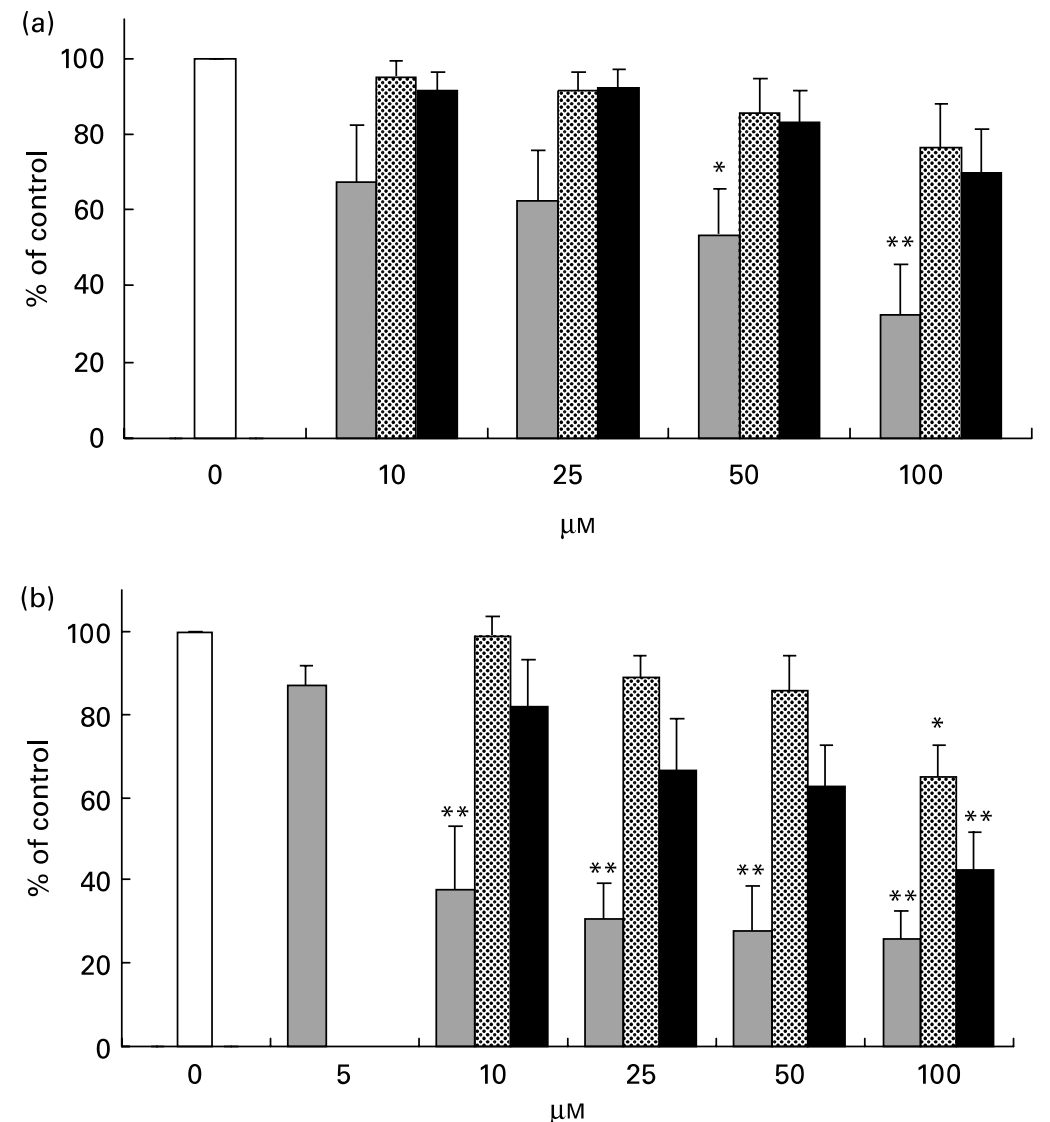

Fig. 2. Effect of solvent $(\square)$, genistein $(\square)$, daidzein (漛) and equol ( $\square$ ) on polymorphonuclear leukocyte (PMN) homotypic adhesion. PMN were pre-incubated with different concentrations of soya isoflavones or dimethyl sulphoxide (DMSO; control) for 5 min at room temperature. Cell suspension was then stimulated with $1 \mu \mathrm{M}$ - n-formyl-methyl-leucyl-phenylalanine (a) or $25 \mu \mathrm{g} / \mathrm{ml}$ soluble P-selectin (b) for $3 \mathrm{~min}$ in standard conditions. Aliquots of the PMN suspension ( $50 \mu \mathrm{l}$ ) were then fixed with paraformaldehyde ( $1 \%$ final concentration) and the single, non aggregated PMN counted under contrast light microscopy. The numbers of single PMN counted before and after stimulation was used to calculate the percentage of aggregated PMN. Results are presented as \% of control values (from samples treated with DMSO); means with their standard errors of the mean ( $n 5$ for (a); $n 6$ (b)). Mean values were significantly different from control values: $P<0.05$; ${ }^{\star \star} P<0.001$. For details of procedures, see Experimental methods. 


\section{Effect on polymorphonuclear leukocyte-platelet adhesion}

Activated PMN adhered to stimulated platelets in a timedependent manner, reaching a maximum at $1 \mathrm{~min}$. At this time, in DMSO-treated samples (control), the percentage of PMN positive for platelet fluorescence marker $(\%(+) \mathrm{PMN})$ was 58 (SEM 12) \% ( $n$ 4) and the number of platelets adherent to $100 \mathrm{PMN}$ (platelets/100 PMN) was 464 (SEM 161) ( $n$ 4). Genistein, daidzein and equol reduced in a concentrationdependent manner the ability of PMN to adhere to thrombin-activated platelets with $\mathrm{IC}_{50} 4 \cdot 0$ (SEM 0.9), 47 (SEM 6) and 66 (SEM 23) $\mu \mathrm{M}$, respectively, when considering the number of platelets carried by $100 \mathrm{PMN}(n 4$, Fig. 3$)$. The percentage of $(+)$ PMN was reduced to $16 \cdot 0$ (SEM 3.4), 32 (SEM 7), 36 (SEM 13) and the number of platelets/100 PMN to 38 (SEM 5), 122 (SEM 31) and 166 (SEM 72), after pre-incubation of PMN with $100 \mu \mathrm{M}$ genistein, daidzein, and equol, respectively.

Effect on the expression of the $\beta 2$-integrin Mac-1 induced by $n$-formyl-methyl-leucyl-phenylalanine on polymorphonuclear leukocyte surface

The mean fluorescence (arbitrary units) of PMN population increased from a basal value of 18 (SEM 1) to 59 (SEM 6) $(n$ 4) upon stimulation with $1 \mu \mathrm{M}-\mathrm{fMLP}$.

Preincubation of PMN with genistein, daidzein or equol, at the highest concentration tested $(100 \mu \mathrm{M})$, did not significantly modify basal or fMLP-induced Mac-1 expression (data not shown).

\section{Effect on protein Pyk2 tyrosine phosphorylation}

We and others have identified the tyrosine kinase Pyk2 as a possible mediator of oxidative burst and of $\beta 2$-integrin adhesive function in $\mathrm{PMN}^{20-22}$. Therefore, we analysed the effect of soya isoflavones on Pyk2 phosphorylation in PMN challenged by fMLP or P-selectin.

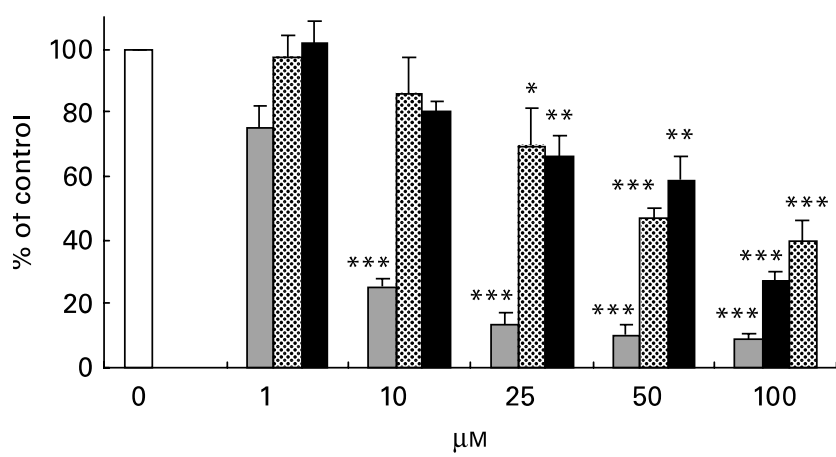

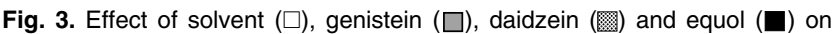
the adhesion between unstimulated polymorphonuclear leukocytes (PMN) and thrombin-stimulated, fixed platelets. Hydroxyetidine-PMN, pre-incubated with different concentrations of soya isoflavones or dimethyl sulphoxide (control) for $5 \mathrm{~min}$, were mixed with thrombin-stimulated paraformaldehyde-fixed BCECF-platelets by stirring at $1000 \mathrm{rpm}$. The formation of mixed platelet$\mathrm{PMN}$ conjugates was evaluated and presented as the relative number of platelets carried by $100 \mathrm{PMN}$. Results are presented as \% of control values; means with their standard error of the mean $(n 3)$. Mean values were significantly different from control values: ${ }^{\star} P<0.05$; ${ }^{\star \star} P<0.01$; ${ }^{\star \star \star} P<0.001$. For details of procedures, see Experimental methods.
The level of Pyk2 phosphorylation in fMLP-stimulated PMN was reduced by preincubation with $100 \mu \mathrm{M}$ genistein, daidzein or equol (Fig. 4(a)). Similar results were obtained when PMN were stimulated with P-selectin (Fig. 4(b)).

\section{Discussion}

In the present study, we show that the soya isoflavones genistein, daidzein and equol inhibit at a different extent several PMN functions contributing to the pathogenesis and evolution of $\mathrm{CHD}$

The concentrations of soya isoflavones required for the in vitro inhibitory activities described in the present paper are higher than those reached in plasma of human subjects and experimental animals after short-term as well as prolonged administration. However, isoflavones may accumulate in tissues, reaching there concentrations much higher than those measured in serum ${ }^{23}$. Regular consumption of soya products, together with other polyphenol-rich foods, such as fruits and vegetables, might further increase isoflavone concentrations within the blood circulation and/or relevant tissues.

In recent years, evidence has been presented on the beneficial effect of soya isoflavones on CVD risk and mortality ${ }^{24}$. The mechanisms by which these compounds may prevent or reduce atherosclerosis include improvement in lipid profile ${ }^{25}$, antioxidant activity ${ }^{26}$, vascular relaxation ${ }^{27}$ and inhibition of platelet aggregation $^{28}$.

All three isoflavones, genistein in particular, exerted a potent antioxidant effect on superoxide anions produced by fMLP-stimulated PMN. Toxic oxygen metabolites, which mediate cellular injury by initiating membrane lipid peroxidation, induce endothelial cell damage, activation of both endothelial cells and platelets and alteration of vascular permeability $^{29,30}$.

Isoflavones exert antioxidant effects in vitro and in vivo. Human consumption of soya containing naturally occurring phyto-oestrogens reduced lipid peroxidation in vivo and increased resistance of LDL to oxidation ${ }^{31}$. Genistein increases activity of antioxidant enzymes, such as catalase, superoxide dismutase, glutathione peroxidase and glutathione reductase $^{32}$. The present results confirm the antioxidant properties of soya isoflavones and show that they also inhibit, at very low concentrations, the production of superoxide anions by fMLP-stimulated PMN, but not by PMA, the direct protein kinase $\mathrm{C}$ activator. This indicates that the antioxidant effect is not due to a scavenger action of the compounds, but is instead mediated by inhibition of signalling step(s), necessary for NADPH oxidase activation, which are upstream to or independent from protein kinase $\mathrm{C}$. This also might explain the different effect of genistein and daidzein and equol on fMLP-induced superoxide anion production.

At higher concentrations, genistein also inhibited the release of elastase from PMN activated by fMLP. Proteolytic enzymes released from neutrophil cytoplasmic granules are responsible for various effects leading to vascular damage. Elastase causes detachment or lysis of endothelial cells and degradation of subendothelial matrices and stimulates endothelial cell secretion of growth factors for smooth muscle cells ${ }^{33}$. As increased plasma levels of elastase were reported in acute IHD and after coronary angioplasty ${ }^{34,35}$, proteases released 
(a)

fMLP

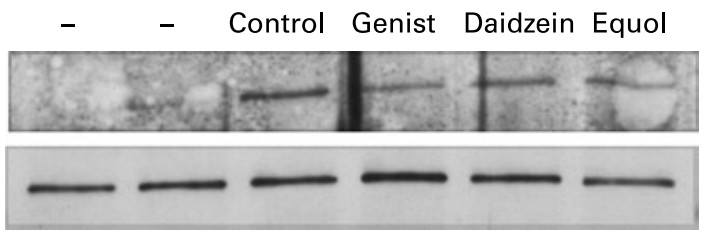

P-Sel

$37^{\circ} \mathrm{C}$ w.b.

Anti-PY

Anti-Pyk2

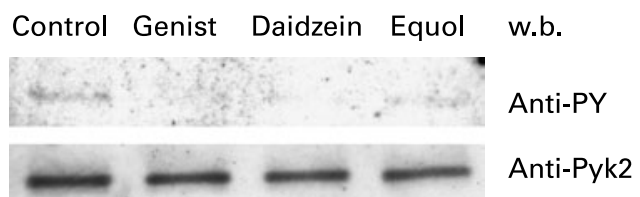

Fig. 4. Effect of genistein, daidzein and equol on Pyk2 tyrosine phosphorylation in polymorphonuclear leukocytes (PMN) stimulated with (a) $n$-formyl-methyl-leucylphenylalanine (fMLP) and (b) P-selectin. PMN were pre-incubated with soya isoflavones or dimethyl sulphoxide (control) for 5 min before stimulation with $1 \mu \mathrm{M}$-fMLP or $25 \mu \mathrm{g} / \mathrm{ml}$ soluble P-selectin. The reaction was stopped after $3 \mathrm{~min}$ by adding an equal volume of $2 \times$ reducing Laemmli's buffer and samples were processed. Pyk2 was immunoprecipitated from lysates, immune complexes were analysed for phospho-Pyk2 by immunoblotting with PY99 (anti-PY) and then the blots were reprobed with anti-Pyk2 antibody to detect total Pyk2. The figure is representative of results obtained in two different experiments. For details of procedures, see Experimental methods.

by activated PMN at the level of coronary vessels might be involved in the progression of vascular disease.

Localization of PMN at sites of inflammatory reactions or thrombus formation is mediated by adhesion receptors of the $\beta 2$ integrin family, such as the CD11b-CD18 Mac-1. These molecules are constitutively expressed on PMN surface and also stored in secretory granules. Upon inflammatory activation, Mac-1 is rapidly translocated from the intracellular pools to the cell surface and, in parallel, conformational changes within the molecule allow competent binding to its counter receptors on PMN (homotypic cell adhesion), as well as on platelets and on vascular cell surface (heterotypic cell adhesion $)^{36}$. In particular, PMN adhesion to platelets is coordinated by an adhesion cascade in which the glycoprotein P-selectin expressed on the surface of activated platelets binds to P-selectin glycoprotein ligand-1 on PMN to promote the initial tethering of the cells, followed by subsequent firm adhesion mediated by Mac-1 binding to its counter receptors on platelets.

In our system, genistein, equol and daidzein prevented PMN homotypic aggregation induced either by the chemotactic peptide fMLP or by soluble human P-selectin, as well as the formation of PMN/platelet aggregates in mixed cell suspension. However, they did not impair Mac-1 translocation from intracellular stores to PMN surface, indicating that they may interfere with the intracellular signalling that allows competent binding of Mac-1 to its counter receptors, which is necessary for an efficient cell-cell adhesion to occur. In agreement with the present data, soya isoflavones (genistein, daizein and equol or sera from soya diet-fed rats) inhibited monocyte adhesion to endothelial cell specific CD54, by blocking the affinity regulation of $\mathrm{CD} 11 \mathrm{a}^{37}$.

Isoflavones, especially genistein, have been shown to inhibit cellular tyrosine kinases ${ }^{38}$; however, the specific targets that may explain the biological effects of these compounds remain largely unknown.

Previous studies from our laboratory showed that pharmacological blockade of Pyk2 impairs the ability of PMN to adhere with activated platelets, indicating that Pyk2 may mediate Mac-1 activation during platelet-PMN interaction ${ }^{22}$. The present results showing that Pyk-2 phosphorylation is inhibited by soya isoflavones suggest that Pyk 2 may be a novel candidate target to explain the effects of these compounds on PMN adhesive behaviour. Interestingly, Pyk2 appears to be an important mediator of activation and function NADPH complex $^{21}$ in adherent PMN. Thus, Pyk2 blockade might also explain the inhibitory effects of isoflavones on superoxide anion production.

In summary, the present study offers new experimental support to the biological plausibility of the epidemiological finding that soya consumption decreases CVD morbidity and mortality ${ }^{39}$. The beneficial effect of soya food might be linked to the biological properties of isoflavones. In addition to being antioxidant and platelet inhibitors, these compounds also appeared to significantly reduce potential mechanisms of vascular ischaemic disease, such as PMN activation and platelet-PMN interaction.

Although evidence for the beneficial effects of soya isoflavones is increasing, further studies are needed. Controlled, randomized clinical trials are necessary to determine their safety and identify the population(s) who can benefit most from the use of these compounds.

\section{Acknowledgements}

We thank Professor Giovanni de Gaetano, Catholic University at Campobasso, for helpful discussion and critical review of the manuscript. Katarzyna Krauze-Brzósko was the recipient of a Marie Curie Host Fellowship of the European Union (Contract N. QLK4-CT-2000-60 029). This work was partially supported by Indena $\mathrm{SpA}$, Milano, Italy and by the Italian Ministry of University and Research (MIUR, Programma Triennale Ricerca, decreto 1588, to C.C. and M.B.D.). 


\section{References}

1. Ernst E, Hammerschmidt DE, Bagge U, Matrai A \& Dormandy JA (1987) Leukocytes and the risk of ischemic diseases. JAMA 257, 2318-2324.

2. Danesh J, Collins R, Appleby P \& Peto R (1998) Association of fibrinogen, C-reactive protein, albumin, or leukocyte count with coronary heart disease: meta-analyses of prospective studies. JAMA 279, 1477-1482.

3. Cerletti C, Evangelista V, Lorenzet R \& de Gaetano G (2002) Platelet-leukocyte interactions relevant to vascular damage and thrombosis. In Platelets in Thrombotic and Non Thrombotic Disorders, pp. 412-431 [P Gresele, CP Page, V Fuster and J Vermylen, editors]. Cambridge: Cambridge University Press.

4. Meisel SR, Shapiro H, Radnay J, Neuman Y, Khaskia AR, Gruener N, Pauzner H \& David D (1998) Increased expression of neutrophil and monocyte adhesion molecules LFA-1 and Mac1 and their ligand ICAM-1 and VLA-4 throughout the acute phase of myocardial infarction: possible implications for leukocyte aggregation and microvascular plugging. $J$ Am Coll Cardiol 31, 120-125.

5. Mickelson JK, Ali MN, Kleiman NS, Lakkis NM, Chow TW, Hughes BJ \& Smith CW (1999) Chimeric 7E3 Fab (ReoPro) decreases detectable CD11b on neutrophils from patients undergoing coronary angioplasty. $\mathrm{J} \mathrm{Am}$ Coll Cardiol 33, 97-106.

6. Merhi Y, Provost P, Guidoin R \& Latour JG (1997) Importance of platelets in neutrophil adhesion and vasoconstriction after deep carotid arterial injury by angioplasty in pigs. Arterioscler Thromb Vasc Biol 17, 1185-1191.

7. Bednar M, Smith B, Pinto A \& Mullane KM (1985) Neutrophil depletion suppresses in-labeled platelet accumulation in infarcted myocardium. J Cardiovasc Pharmacol 7, 906-912.

8. de Lorgeril M, Basmadjian A, Lavallee M, Clement R, Millette D, Rousseau G \& Latour JG (1989) Influence of leukopenia on collateral flow, reperfusion flow, reflow ventricular fibrillation, and infarct size in dogs. Am Heart J 117, 523-532.

9. Simpson PJ, Todd RFIII, Fantone JC, Mickelson JK, Griffin JD \& Lucchesi BR (1988) Reduction of experimental canine myocardial reperfusion injury by a monoclonal antibody (anti-Mo1, anti-CD 11b) that inhibits leukocyte adhesion. J Clin Invest $\mathbf{8 1}$, 624-629.

10. Cerletti C, Evangelista V, Molino M \& de Gaetano G (1995) Platelet activation by polymorphonuclear leukocytes: role of cathepsin G and P-selectin. Thromb Haemost 74, 218-223.

11. Beaglehole R (1990) International trends in coronary heart disease mortality, morbidity, and risk factors. Epidemiol Rev 12, $1-15$.

12. Glazier MG \& Bowman MA (2001) A review of the evidence for the use of phytoestrogens as a replacement for traditional estrogen replacement therapy. Arch Intern Med 161, $1161-1172$.

13. Setchell KDR (1998) Phytoestrogens: the biochemistry, physiology, and implications for human health of soy isoflavones. Am J Clin Nutr 68, Suppl., 1333S-1346S.

14. Evangelista V, Rajtar G, de Gaetano G, White JG \& Cerletti C (1991) Platelet activation by fMLP-stimulated polymorphonuclear leukocytes: the activity of cathepsin $\mathrm{G}$ is not prevented by antiproteinases. Blood 77, 2379-2388.

15. Remuzzi A, Languino LR, Costantini V, Guardabasso V, de Gaetano G \& Dejana E (1985) Platelet adhesion to subendothelium: effect of shear rate, hematocrit and platelet count on the dynamic equilibrium between platelets adhering to and detaching from the surface. Thromb Haemost 54, $857-861$.
16. Bazzoni G, Dejana E \& Del Maschio A (1991) Adrenergic modulation of human polymorphonuclear leukocyte activation. Potentiating effect of adenosine. Blood 77, 2042-2048.

17. Evangelista V, Manarini S, Rotondo S, Martelli N, Polischuk R, McGregor JL, de Gaetano G \& Cerletti C (1996) Platelet/polymorphonuclear leukocyte interaction in dynamic conditions: evidence of adhesion cascade and cross talk between P-selectin and the $\beta 2$ integrin CD11b/CD18. Blood 88, 4183-4194.

18. Evangelista V, Manarini S, Sideri R, et al. (1999) Platelet/polymorphonuclear leukocyte interaction: P-selectin triggers protein tyrosine phosphorylation-dependent CD11b/CD18 adhesion: role of PSGL-1 as a signaling molecule. Blood $\mathbf{9 3}, 876-885$.

19. Piccardoni P, Sideri R, Manarini S, Piccoli A, Martelli N, de Gaetano G, Cerletti C \& Evangelista V (2001) Platelet/polymorphonuclear leukocyte adhesion: a new role for SRC kinases in Mac-1 adhesive function triggered by P-selectin. Blood 98, $108-116$.

20. Totani L, Piccoli A, Manarini S, et al. (2006) Src-family kinases mediate an outside-in signal necessary for beta2 integrins to achieve full activation and sustain firm adhesion of polymorphonuclear leukocytes tethered on E-selectin. Biochem $J$ 396, 89-98.

21. Han H, Fuortes M \& Nathan C (2003) Critical role of the carboxyl terminus of proline-rich tyrosine kinase (Pyk2) in the activation of human neutrophils by tumor necrosis factor: separation of signals for the respiratory burst and degranulation. J Exp Med 197, 63-75.

22. Evangelista V, Pamuklar Z, Piccoli A, et al. (2007) Src family kinases mediate neutrophil adhesion to adherent platelets. Blood 109, 2461-2469.

23. Chang HC, Churchwell MI, Delclos B, Newbold RR \& Doerge DR (2000) Mass spectrometric determination of genistein tissue distribution in diet-exposed Sprague-Dawley rats. J Nutr 130, 1963-1970.

24. Anderson JW, Johnstone BM \& Cook-Newell ME (1995) Metaanalysis of the effects of soy protein intake on serum lipids. $N$ Engl J Med 333, 276-282.

25. Ruiz-Larrea MB, Mohan AR, Paganga G, Miller NJ, Bolwell GP \& Rice-Evans CA (1997) Antioxidant activity of phytoestrogenic isoflavones. Free Radic Res 26, 63-70.

26. Mishra SK, Abbot SE, Choudhury Z, Cheng M, Khatab N, Maycock NJ, Zavery A \& Aaronson PI (2000) Endothelium-dependent relaxation of rat aorta and main pulmonary artery by the phytoestrogens genistein and daidzein. Cardiovasc Res 46, $539-546$

27. Gooderham MJ, Adlercreutz H, Ojala ST, Wahala K \& Holub BJ (1996) A soy protein isolate rich in genistein and daidzein and its effects on plasma isoflavone concentrations, platelet aggregation, blood lipids and fatty acid composition of plasma phospholipid in normal man. J Nutr 126, 2000-2006.

28. Diaz MN, Frei B, Vita JA \& Keaney JF (1997) Antioxidants and atherosclerotic heart disease. New Engl J Med 337, 408-416.

29. Finkel T (1998) Oxygen radicals and signaling. Curr Opin Cell Biol 10, 248-253.

30. Ambrosio G, Weisfeldt ML, Jacobus WE \& Flaherty JT (1987) Evidence for a reversible oxygen radical-mediated component of reperfusion injury: reduction by recombinant human superoxide dismutase administered at the time of reflow. Circulation 75, 282-291.

31. Wiseman H, O' Reilly J, Adlercreutz H, Mallet AI, Bowey EA, Rowland IR \& Sanders TAB (2000) Isoflavone phytoestrogens consumed in soy decrease F2-isoprostane concentrations and increase resistance of low-density lipoprotein to oxidation in humans. Am J Clin Nutr 72, 395-400.

32. Wei H (1995) Antioxidant and antipromotional effects of the soybean isoflavone genistein. Proc Soc Exp Med 208, $124-130$. 
33. Vaday GG \& Lider O (2000) Extracellular matrix moieties, cytokines, and enzymes: dynamic effects on immune cell behavior and inflammation. J Leukoc Biol 67, 149-159.

34. Mehta J, Dinerman J, Mehta P, Saldeen TGP, Lawson D, Donnelly WH \& Wallin R (1989) Neutrophil function in ischemic heart disease. Circulation 79, 549-556.

35. De Servi S, Ricevuti G, Mazzone A, Ghio S, Zito A, Raffaghello $S$ \& Specchia G (1991) Granulocyte function in coronary artery disease. Am J Cardiol 68, 64B-68B.

36. Arnaout A (1991) Structure and function of the leukocyte adhesion molecules CD11/CD18. Blood 77, 2042-2048.
37. Nagajaran S, Steward BW \& Badger TM (2006) Soy isoflavones attenuate human monocyte adhesion to endothelial cellspecific CD54 by inhibiting monocyte Cd11a. J Nutr 136, 2384-2390.

38. Akiyama T, Ishida J, Nakagawa $\mathrm{S}$, Ogawara $\mathrm{H}$, Watanabe $\mathrm{S}$, Itoh N, Shibuya M \& Fukami Y (1987) Genistein, a specific inhibitor of tyrosine-specific protein kinases. J Biol Chem 103, 103-112.

39. Erdman JW (2000) Soy protein and cardiovascular disease. A statement for healthcare professionals from the nutrition committee of the AHA. Circulation 102, 2555-2559. 